\title{
Produções agrícola e industrial de cana-de-açúcar \\ submetida a doses de vinhaça ${ }^{1}$
}

\section{Agricultural and industrial yields of sugar cane submitted to vinasse rates}

\author{
Aline Fagote Paulino ${ }^{2 ;}$, Cristiane de Conti Medina ${ }^{3 *}$; Carla Renata Pazotti Robaina ${ }^{4}$; \\ Raffael Alberto Laurani²
}

\begin{abstract}
Resumo
O objetivo deste trabalho foi avaliar a influência de doses de vinhaça nas produções agrícola e industrial da cana-de-açúcar. O ensaio foi conduzido na Fazenda Escola da Universidade Estadual de Londrina, em Latossolo Vermelho, no período de 1994 a 1999, com delineamento em blocos ao acaso. Os tratamentos constituíram-se de 5 doses de vinhaça: $\mathrm{T}_{1}=0 \mathrm{~m}^{3} \mathrm{ha}^{-1}, \mathrm{~T}_{2}=150 \mathrm{~m}^{3} \mathrm{ha}^{-1}, \mathrm{~T}_{3}=300 \mathrm{~m}^{3} \mathrm{ha}^{-1}, \mathrm{~T}_{4}=450$ $\mathrm{m}^{3} \mathrm{ha}^{-1}, \mathrm{~T}_{5}=600 \mathrm{~m}^{3} \mathrm{ha}^{-1}$, e 4 repetições por tratamento. Para o presente trabalho foram utilizados dados referentes às $4^{\mathrm{a}}$ e $5^{\mathrm{a}}$ colheitas $\left(3^{\mathrm{a}}\right.$ e $4^{\mathrm{a}}$ socas), sendo avaliadas as produtividades agrícola $\left(\mathrm{t} \mathrm{h} \mathrm{h}^{-1}\right) \mathrm{e}$ industrial ( $\mathrm{t}$ açúcar ha- $\mathrm{e}^{3}$ álcool ha-1). Utilizou-se a análise de regressão para os dados. Os resultados

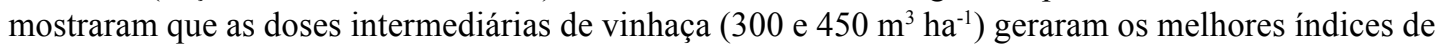
produtividades agrícola e industrial.

Palavras-chave: Saccharum spp, subproduto, produtividade.
\end{abstract}

\begin{abstract}
This study was carried out to assess the influence of vinasse rates on the agricultural and industrial yields of sugar cane. The experiment was set up at the School Farm of the State University of Londrina, in "Latossolo Vermelho" soil (Oxisol), between 1994 and 1999, in a randomized block design with four replications. Treatments were based of five rates of vinasse applied to the soil: $\mathrm{T}_{1}=0 \mathrm{~m}^{3} \mathrm{ha}^{-1}, \mathrm{~T}_{2}=150$ $\mathrm{m}^{3} \mathrm{ha}^{-1}, \mathrm{~T}_{3}=300 \mathrm{~m}^{3} \mathrm{ha}^{-1}, \mathrm{~T}_{4}=450 \mathrm{~m}^{3} \mathrm{ha}^{-1}, \mathrm{~T}_{5}=600 \mathrm{~m}^{3} \mathrm{ha}^{-1}$. This study is accomplishes the fourth and the fifth harvesting ( $3^{\mathrm{a}}$ and $4^{\mathrm{a}}$ stump) and the following parameters were evaluated: agricultural (ton $\left.\mathrm{ha}^{-1}\right)$ and industrial yield (ton ha-1 of sugar and $\mathrm{m}^{3} \mathrm{ha}^{-1}$ of alcohol). The results showed that the intermediary rates (300 and $\left.450 \mathrm{~m}^{3} \mathrm{ha}^{-1}\right)$ gave provided better results for agricultural and industrial yield.
\end{abstract}

Key Words: Saccharum spp, by product, yield.

\footnotetext{
Parte da tese de Doutorado de Carla Renata Pazotti Robaina.

2 Alunos de Mestrado do Programa do Pós-graduação em Agronomia - UEL;

3 Professora do Departamento Agronomia, UEL, C.P. 6001, CEP 86.051-990, Londrina, PR., Tel. 43 3371-4555, E-mail: medina@uel.br

4 Doutoranda junto a FCA-UNESP

* Autor para correspondência.
} 


\section{Introdução}

A vinhaça é um resíduo da fabricação do álcool, gerado a uma proporção média de 13 litros para cada litro de álcool produzido e caracterizado por alta demanda bioquímica de oxigênio (DBO), consumindo de 12000 a $20000 \mathrm{mg}$ de oxigênio por litro para estabilização das substâncias putrescíveis (SILVA; SILVA, 1986; FREIRE; CORTEZ, 2000). Devido ao seu alto poder poluidor, sua eliminação era um problema para as indústrias.

Hoje, entretanto, a aplicação da vinhaça no canavial, como fertirrigação, é prática muito difundida entre as usinas e destilarias brasileiras. Penatti et al. (1988) citam que o uso de vinhaça traz resultados positivos na produtividade agrícola da cana, além de gerar economia com a aquisição de fertilizantes. Freire e Cortez (2000) citam que a vinhaça proporciona benefícios biológicos, físicos e químicos ao solo, refletindo em maiores produtividades. Entretanto, se aplicada em excesso, pode causar sérias alterações na qualidade da matéria-prima para a indústria, como a diminuição da qualidade tecnológica do caldo.

A necessidade da adubação das soqueiras de canade-açúcar é indiscutível, tendo em vista que, em cada ciclo, a planta retira do solo quantidades apreciáveis de nutrientes, que necessitam ser restituídos através da adubação. A vinhaça tem possibilidades de fornecer parte desses nutrientes requeridos pela soqueira, onde seu emprego deve ser prioritário, pelo fato de sua disponibilidade ocorrer no período da safra (SANTANA, 1985).

A vinhaça pode ser empregada como fertilizante orgânico, contendo alto teor de matéria orgânica, potássio e água, sendo relativamente pobre em nitrogênio e cálcio, com baixos teores de fósforo e magnésio (PENATTI et al., 1988).

A cana é altamente exigente em potássio e sua carência reflete não apenas na diminuição da biomassa produzida, como também no menor acúmulo de açúcares no colmo, explicado pela menor fotossíntese e pela menor translocação (GLÓ-
RIA, 1985). Ocorre, também, diminuição do crescimento e do perfilhamento da cana, além da formação de colmos mais finos com internódios mais curtos (ORLANDO FILHO, 1977).

O potássio é o cátion predominante e de maior importância na vinhaça (RODELLA; FERRARI, 1977; FREIRE; CORTEZ, 2000). Assim como sua deficiência pode causar sérios problemas, o excesso do elemento pode induzir à falta de magnésio (MALAVOLTA; VITTI; OLIVEIRA, 1989) e aumentar o teor de cinzas no caldo (CASAGRANDE, 1991).

A aplicação de vinhaça nas lavouras aumenta a produtividade da cultura, e, paralelamente, reduz a concentração de açúcar no caldo (FREIRE, CORTEZ, 2000). Este efeito depreciativo pode ser devido, justamente, ao crescimento vegetativo mais vigoroso, o que leva a atraso na maturação (KORNDORFER, 1990).

SILVA et al. (1978) citam que, ao se aplicar vinhaça, deve-se ter prévio conhecimento da dose adequada, pois tanto a produtividade, quanto a qualidade tecnológica da cana-de-açúcar são influenciadas por estas aplicações.

O objetivo deste trabalho foi avaliar o efeito de doses de vinhaça nas produções agrícola e industrial da cana-de-açúcar.

\section{Material e Métodos}

O experimento foi conduzido no período de agosto de 1994 a agosto de 1999, na Fazenda Escola da Universidade Estadual de Londrina, Paraná, em Latossolo Vermelho, situado à latitude de $23^{\circ} 23^{\prime} \mathrm{S}$, longitude de $51^{\circ} 11^{\prime} \mathrm{W}$ e altitude de 566 metros. O clima da região é subtropical úmido, com chuvas em todas as estações, podendo ocorrer seca no período de inverno. A temperatura média anual é de $20,7^{\circ} \mathrm{C}$. A incidência média de radiação solar anual é de 7,05 $\mathrm{h} \mathrm{dia}^{1}$ (CORREAA; GODOY; BERNARDES, 1982).

O plantio foi feito em 1994, após preparo convencional do solo: uma aração, duas gradagens e abertura dos sulcos. Com base na análise química 
do solo (Tabela 1), no sulco de plantio aplicou-se 20 $\mathrm{kg} \mathrm{ha}{ }^{-1}$ de $\mathrm{N}, 90 \mathrm{~kg} \mathrm{ha}^{-1}$ de $\mathrm{P}_{2} \mathrm{O}_{5}$ e $90 \mathrm{~kg} \mathrm{ha}^{-1}$ de $\mathrm{K}_{2} \mathrm{O}$, respectivamente, uréia, superfosfato simples e cloreto de potássio. Sessenta dias após o plantio, foi realizada adubação de cobertura com $50 \mathrm{~kg} \mathrm{ha}^{-1}$ de uréia.

Tabela 1 - Análise química do solo, no ano de 1994.

\begin{tabular}{ccccccccccc}
\hline Prof. & $\mathbf{p H}$ & $\mathbf{M . O}$ & $\mathbf{P}$ & $\mathbf{H}+\mathbf{A l}$ & $\mathbf{K}$ & $\mathbf{C a}$ & $\mathbf{M g}$ & $\mathbf{S B}$ & $\mathbf{C T C}$ & $\mathbf{V}$ \\
\hline $\mathbf{m}$ & $\mathbf{C a C l}_{\mathbf{2}}$ & $\mathbf{g ~ k g}^{-\mathbf{1}}$ & $\mathbf{\mathbf { m g ~ d m } ^ { - 3 }}$ & & & $\mathbf{c m o l}_{\mathbf{c}} \mathbf{d m}^{-3}$ & & & \% \\
\hline $\mathbf{0 - 0 , 2 0}$ & 5,4 & 31,1 & 11,4 & 3,3 & 0,64 & 5,6 & 1,9 & 8,2 & 11,5 & 71 \\
$\mathbf{0 , 2 0 - 0 , 4 0}$ & 5,1 & 22,4 & 6,7 & 4,2 & 0,89 & 4,2 & 1,6 & 6,7 & 10,0 & 59 \\
$\mathbf{0 , 4 0 - 0 , 6 0}$ & 5,1 & 18,4 & 4,0 & 3,5 & 0,71 & 4,6 & 0,9 & 6,2 & 9,0 & 61 \\
\hline
\end{tabular}

Durante o período de condução do estudo, não se realizou operações com maquinaria agrícola, a fim de minimizar a compactação. Através de capinas manuais mensais, a cultura foi mantida livre de plantas daninhas até 90 dias após o plantio.

A variedade de cana-de-açúcar plantada foi a RB785148 e sua curva de maturação encontra-se na Figura 1. A utilização desta variedade deu-se em função de sua adaptação e da grande área cultivada na região de condução do estudo.

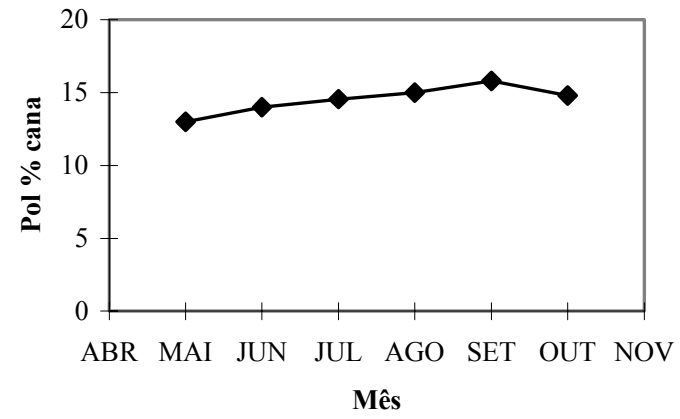

Figura 1 - Curva de maturação da variedade RB785148, realizada com dados da área experimental na safra 96/97.

A vinhaça de mosto misto passou a ser aplicada manualmente a partir de 1995, 1 vez ao ano, durante a fase de brotação da soqueira. As doses utilizadas foram: $\mathrm{T}_{1}=0 \mathrm{~m}^{3} \mathrm{ha}^{-1} ; \mathrm{T}_{2}=150 \mathrm{~m}^{3} \mathrm{ha}^{-1} ; \mathrm{T}_{3}=300 \mathrm{~m}^{3}$ ha $^{-1} ; \mathrm{T}_{4}=450 \mathrm{~m}^{3} \mathrm{ha}^{-1} ; \mathrm{T}_{5}=600 \mathrm{~m}^{3} \mathrm{ha}^{-1}$. A composição química média da vinhaça, segundo análise feita pelo Laboratório Laborsolo (Londrina-PR), encontra-se na Tabela 2.
Tabela 2 - Composição química média da vinhaça de mosto misto.

\begin{tabular}{ccccccc}
\hline Disponível & $\mathbf{N}$ & $\mathbf{P}_{\mathbf{2}} \mathbf{O}_{\mathbf{5}}$ & $\mathbf{K}_{\mathbf{2}} \mathbf{O}$ & $\mathbf{C a}$ & $\mathbf{M g}$ & $\mathbf{S}$ \\
\hline $\mathbf{k g ~ m}^{-3}$ & 0,028 & 0,12 & 2,40 & 1,10 & 0,24 & 5,48 \\
\hline
\end{tabular}

Os resultados apresentados neste estudo são referentes à média dos dados das $4^{\mathrm{a}}$ e $5^{\mathrm{a}}$ colheitas $\left(3^{\mathrm{a}} \mathrm{e}\right.$ $4^{\mathrm{a}}$ socas), realizadas, respectivamente, em agosto de 1998 e em agosto de 1999.

O delineamento experimental utilizado foi o de blocos ao acaso, com 5 tratamentos e 4 repetições. Cada parcela constituiu-se de 5 linhas com $8 \mathrm{~m}$ de comprimento e espaçamento entrelinhas de 1,20 m, resultando em $48 \mathrm{~m}^{2}$ por parcela. Para as avaliações, foram consideradas as 3 linhas centrais da parcela, suprimindo-se 1,50 m em cada extremidade (bordadura), obtendo-se uma área útil de $18 \mathrm{~m}^{2}$ por parcela.

As colheitas foram manuais e realizadas com a cana verde. Para avaliações referentes à produtividade de cana, a área útil da parcela foi colhida inteira $\left(18 \mathrm{~m}^{2}\right)$ e pesada no próprio campo com balança de chão. De cada parcela foram moídos 10 colmos, retirando-se o caldo para as leituras de Pol (\% de sacarose), em polarímetro, e Brix (\% de sólidos solúveis), em refratômetro de mesa. Através destes resultados, calculou-se a Pureza aparente, referente à porcentagem de sacarose aparente nos sólidos so- 
lúveis. Para determinações da Pureza aparente e das produtividades de cana $\left(\mathrm{t} \mathrm{ha}^{-1}\right)$, de açúcar $\left(\mathrm{t} \mathrm{ha}^{-1}\right)$ e de álcool $\left(\mathrm{m}^{3} \mathrm{ha}^{-1}\right)$, foram realizados cálculos de acordo com as seguintes fórmulas:

\section{Pureza aparente $=$ Pol x $100 /$ Brix}

Açúcar $(\mathrm{kg}$ açúcar / t cana $)=$ Pol x $\{1,4-(4,0$ / Pureza aparente) $\}$ x 0,79

T açúcar ha ${ }^{-1}=$ t cana ha ${ }^{-1} \mathrm{x}$ kg açúcar ha-1

Álcool $\left(\mathrm{m}^{3} \mathrm{ha}^{-1}\right)=\mathrm{t}$ açúcar ha ${ }^{-1} \mathrm{x} 0,51 / 0,79$

onde:

$0,51=$ quantidade de etanol em $100 \mathrm{~kg}$ de glicose e $0,79=$ densidade do etanol

Os dados obtidos foram submetidos à análise de regressão.

\section{Resultados e Discussão}

Verifica-se que a produção agrícola aumentou nas dosagens intermediárias (300 e $450 \mathrm{~m}^{3} \mathrm{ha}^{-1}$ de vinhaça) (Figura 2), resultados também conseguidos por Orlando Filho, Bittencourt e Alves (1995), que observaram que a dose de $300 \mathrm{~m}^{3}$ ha-1 foi suficiente para aumentar a produção agrícola da cana. Estes resultados vão ao encontro dos obtidos por Stupiello et al. (1977), que, utilizando doses de vinhaça entre 0 e 210 $\mathrm{m}^{3}$ ha $^{-1}$, observaram aumentos significativos de produtividade, sendo que os maiores aumentos corresponderam às doses mais elevadas.

Os polinômios de regressão resultaram em equações do $2^{\circ}$ grau, indicando que doses intermediárias de vinhaça apresentam resultados superiores às muito baixas e elevadas e que, das doses testadas, a de 300 $\mathrm{m}^{3} \mathrm{ha}^{-1}$ foi a que apresentou os melhores resultados, tanto para a produção agrícola quanto para a indus- trial (produção de açúcar e de álcool). Quanto aos coeficientes de determinação $\left(\mathrm{r}^{2}\right)$, estes apresentaram valores elevados, indicando que grande proporção de variação do eixo y é explicada pela regressão (Figuras 2, 3 e 4).

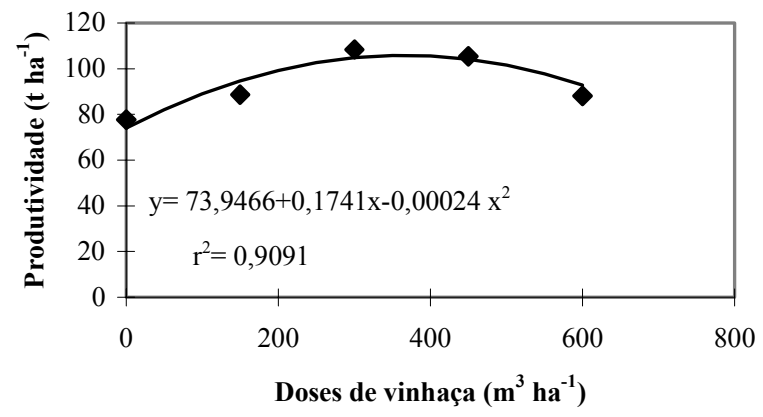

Figura 2 - Produtividade de colmos de cana $\left(\mathrm{t} \mathrm{ha} \mathrm{f}^{-1}\right) \mathrm{em}$ função de diferentes doses de vinhaça aplicadas em fertirrigação em um Latossolo Vermelho (os pontos no gráfico representam médias de dois anos de experimentação - 1998 e 1999 - com a cana em $3^{\text {a }}$ e $4^{\text {a }}$ socas).

Orlando Filho, Bittencourt e Alves (1995), e Stupiello et al. (1977) observaram, na dose de 300 $\mathrm{m}^{3}$ ha $^{-1}$, diminuição na produção industrial da cana, o que não ocorreu neste estudo, visto que, dentre as doses testadas, esta foi a que apresentou melhores resultados (Figuras 3 e 4).

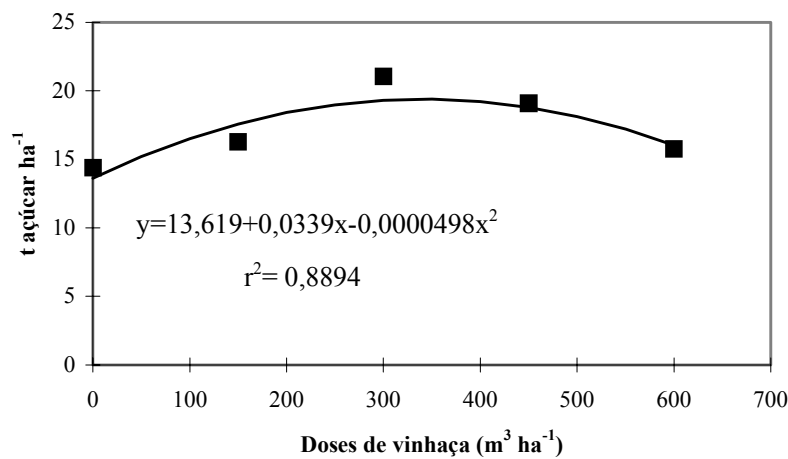

Figura 3 - Produção de açúcar ( $t$ ha $\left.{ }^{-1}\right)$ em função de diferentes doses de vinhaça aplicadas em fertirrigação em um Latossolo Vermelho (os pontos no gráfico representam médias de dois anos de experimentação - 1998 e 1999 - com a cana em $3^{\mathrm{a}}$ e $4^{\mathrm{a}}$ socas). 


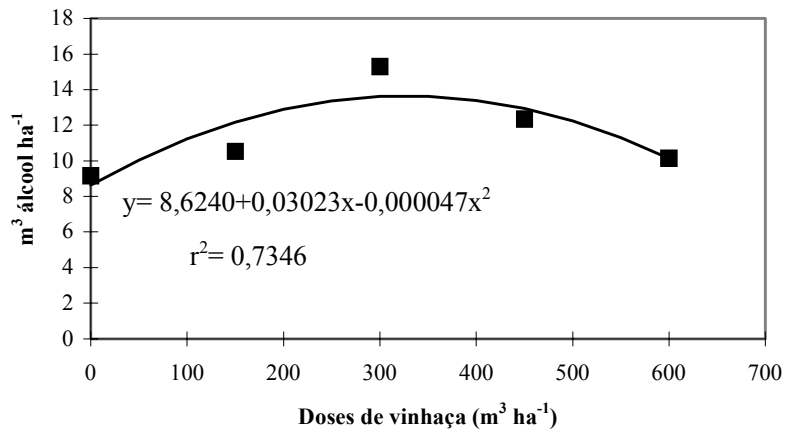

Figura 4 - Produção de álcool $\left(\mathrm{m}^{3} \mathrm{ha}^{-1}\right)$ em função de diferentes doses de vinhaça aplicadas em fertirrigação em um Latossolo Vermelho (os pontos no gráfico representam médias de dois anos de experimentação - 1998 e 1999 - com a cana em $3^{\mathrm{a}}$ e $4^{\mathrm{a}}$ socas).

A aplicação de $600 \mathrm{~m}^{3} \mathrm{ha}^{-1}$ apresentou-se inviável, pois, além de aumentar os custos de produção maiores desgaste de máquinas, mão-de-obra e gasto com combustível -, resultou em produções agrícola e industrial inferiores às doses intermediárias.

\section{Conclusões}

Para as condições do ensaio, conclui-se que maiores produções agrícola e industrial são obtidas com as doses de 300 e $400 \mathrm{~m}^{3}$ ha $^{-1}$.

\section{Referências}

CASAGRANDE, A. A. Tópicos de morfologia e fisiologia da cana-de-açúcar. Jaboticabal: FUNEP, 1991.

CORRÊA, A. R.; GODOY, H.; BERNARDES, L. R. M. Características climáticas de Londrina. Londrina: IAPAR 1982.

FREIRE, W. J.; CORTEZ, L. A. B. Vinhaça de cana-deaçúcar. Guaíra: Livraria e Editora Agropecuária, 2000.
GLÓRIA, N. A. Efeito do potássio na acumulação de sacarose pela cana-de-açúcar. Álcool \& Açúcar, São Paulo, v.5, n.23, p.20-25, 1985.

KORNDORFER, G. H. O potássio e a qualidade da canade-açúcar. Informações Agronômicas, Piracicaba, v.49, p.1-3, 1990.

MALAVOLTA, E.; VITTI, G. C.; OLIVEIRA, S. A. Avaliação do estado nutricional das plantas: princípios e aplicações. Piracicaba: Associação Brasileira para Pesquisa da Potassa e do Fosfato, 1989.

ORLANDO FILHO, J. Nutrição e adubação de canade-açúcar. Brasil Açucareiro, Rio de Janeiro, v.8, n.1, p.10-16, 1977.

ORLANDO FILHO, J.; BITTENCOURT, V .C.; ALVES, M. C. Aplicação de vinhaça em solo arenoso do Brasil e poluição do lençol freático com nitrogênio. Stab, Piracicaba, v.13, n.6, p.14-16, 1995.

PENATTI, C. P. et al. Efeitos da aplicação da vinhaça e nitrogênio na soqueira da cana-de-açúcar. Boletim Técnico Copersucar, São Paulo, v.44, p.32-38, 1988.

RODELLA, A. A.; FERRARI, S. E. A composição da vinhaça e efeitos de sua aplicação como fertilizante na cana-de-açúcar. Brasil Açucareiro, Rio de Janeiro, v.90, n. 7, p.380-387, 1977.

SANTANA, S. S. Economicidade da aplicação de vinhaça em comparação à adubação mineral. Álcool \& Açúcar, São Paulo, v.5, n.23, p.26-38, 1985.

SILVA, G. M. A. et al. Efeitos da aplicação da vinhaça como fertilizante em cana-de-açúcar. Boletim Técnico Copersucar, São Paulo, v.7, p.9-14, 1978.

SILVA, M. A.; SILVA G. L. Utilização agrícola da vinhaça e outros efluentes líquidos. Álcool \& Açúcar, São Paulo, v.5, n.23, p.26-38, 1986.

STUPIELLO, P. et al. Efeitos da aplicação da vinhaça como fertilizante na qualidade da cana-de-açúcar. Brasil Açucareiro, Rio de Janeiro, v.33, n.11, p.41-49, 1977. 
